\title{
Association between voice disorder and breathing alteration in children
}

\author{
Cristiane Marangom ${ }^{(1)}$ \\ Viviani Souza Peruchi ${ }^{(1)}$ \\ Marta Assumpção de Andrada e Silva(1) \\ Irene Queiroz Marchesan(2) \\ Léslie Piccolotto Ferreira ${ }^{(1)}$
}

Pontifícia Universidade Católica de São Paulo - PUC/SP, São Paulo, São Paulo, Brasil.

(2) CEFAC - Saúde e Educação, São Paulo, São Paulo, Brasil.

Research support source: CAPES

scholarship, CNPq.

Conflict of interests: Nonexistent

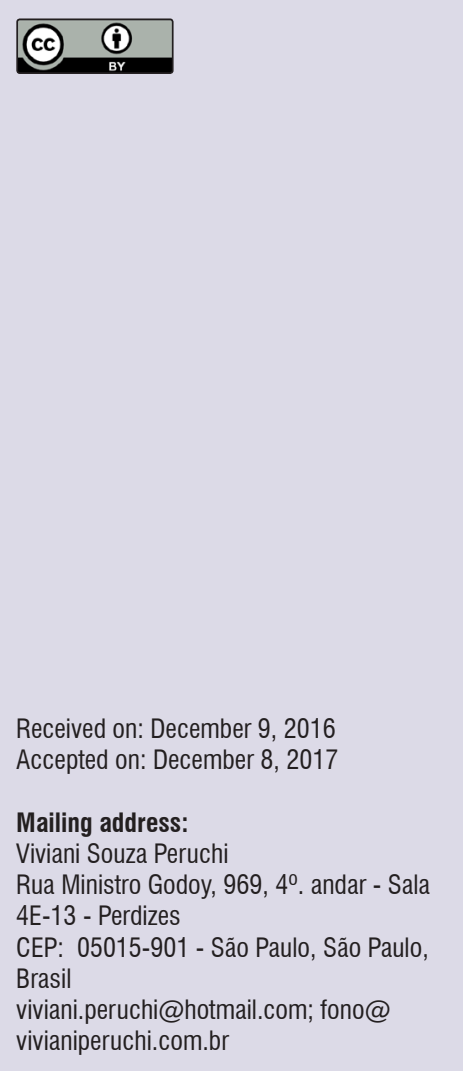

\section{ABSTRACT}

Objective: to analyze the association between voice disorder and aspects related to breathing mode in children, according to sex.

Methods: 250 children, aged six to nine years, attending a public school in São Paulo city, were selected. The collection consisted of spontaneously audio recorded speech samples. The breathing mode was evaluated for lip resting posture and nasal flow. Three audiologists performed the perceptual evaluation of the voice quality, with the help of GIRBAS scale. The results were associated using the chi-square test ( $p=$ 0.05).

Results: $50.4 \%$ females and $49.6 \%$ males. As for the overall grade $(G), 12.8 \%$ had voice disorder with respect to voice quality. In the breathing mode, $36.8 \%$ presented alterations in lip posture and $71.2 \%$, in nasal flow. The associations between voice disorder and gender $(p=0.96)$, lip posture $(p=0.38)$ and nasal flow $(p=0.18)$ and between alterations in the nasal flow and sex $(p=0.449)$ were not confirmed. The association between lip posture and sex revealed significant differences in favor of males $(p=0.003)$.

Conclusion: there was no statistically significant difference associating voice disorders with breathing mode (lip posture and nasal flow) and gender.

Keywords: Voice; Voice Disorders; Respiration; Child 


\section{INTRODUCTION}

Since the beginning in the voice field, the speechlanguage therapy shows a more directed acting in therapeutic clinical issues. In recent years, a particular focus is being provided to the wellness promotion and vocal changes prevention ${ }^{1}$; however, this work is directed to adults, while only few studies address children's voice'.

The daily lives of children seems to contribute to the improper use of the voice in the stage when the vocal apparatus is still under development. Since they are immersed in noisy places, in context of competition, and sometimes they don't have limits set by parents or educators, children can develop vocal disorders. Nodules are most frequent lesions predominantly in boys under 12 years, and girls from this age on ${ }^{2}$.

The childhood is the best time for early detection of disorders, as the impact will be lower on communication ${ }^{3,4}$, it is possible to plan actions to raise awareness regarding the importance of communication and special care to vocal well-being, as well as to guide parents and educators that highlight little importance to vocal disorders ${ }^{3}$.

School environment is one of the places where children make intensive use of voice ${ }^{5}$. Thus, it facilitates the data collection for researches that aim to detect and analyze changes and, as a result, implementing programs to reverse the disorders recorded.

Voice is a dynamic process, which in turn can be influenced by some factors, such as, age, gender, social conditions, health and hydration. There's also the emotional factor, since the individual is able to clearly demonstrate, in their voice emission ${ }^{6-8}$ and, above all, in the personality characteristics, integrity of phonoarticulatory organs (lips, tongue, and cheeks), larynx, resonance boxes and breathing.

In speech-language therapy, the breath practice includes aspects regarding mode, type and pneumophonoarticulatory coordination (CPFA). It is common to work with the CPFA and the type in voice disorders clinic, since the thoracic breathing generates excessive tension in the pharynx and insufficient air supply, which causes tension in the cervical region and harms the good vocal performance ${ }^{9}$.

The breathing mode is the most studied and developed by speech-language therapists who work in the orofacial motricity field ${ }^{10-12}$, especially in children with predominantly oral breathing pattern, who also present changes in swallowing, inefficient chewing, hypotonia in tongue, lips and cheeks.
A research that studied the relationship between dysphonia, breathing pattern (type and mode) and changes in the oral motor sensory system concluded that the upper breathing type is the most recorded in medical records of dysphonic children and it was also the mode most associated with changes in the oral motor sensory system ${ }^{13}$.

Therefore, it is noted that the work related to breathing may be inserted into the therapeutic process in voice disorders, orofacial motricity, and also in some approaches targeted to the treatment of dysfluency. However, even when the treatment is not targeted to voice issues, it can be noted that the breathing pattern, when regarded as predominantly oral, determines an increased effort of the vocal emission of the child, a fact which may cause an overload in the larynx and may also contribute for the presence of a vocal disorder ${ }^{14}$.

The mouth breathing habit can trigger several postural changes such as: hips toward the front of the body, body weight supported on the abdomen, shoulders rotated forward and head towards the front of the body ${ }^{15}$.

Among other possible changes in the breathing and vocal tract relationship, it is possible to highlight the occlusal, which happens when the tongue may be positioned in a compensatory way between dental arches, being fully rested at the bottom of the mouth, or with the back of the tongue high and the end of the tongue low to facilitate the air intake, in which situation the mouth takes over the function of the nose ${ }^{16}$.

In this way, the lips lose the contact, which affects the resonance and dryness of the vocal tract mucosa and larynx tissues, and also hinders vocal fold vibration.

Some studies present data of vocal disorders in children, with emphasis on changes in vocal quality, increased intensity and cervical tension to phonation ${ }^{17,18}$. These changes may cause an unfavorable impact with respects to aspects of the communication efficiency, social development and self-esteem in children and adolescents ${ }^{4}$.

Although some studies report data related to the main myofunctional changes of phonoarticulatory organs, which are characterized by predominantly oral breathing ${ }^{19}$, only few studies associate the voice with the breathing mode in children ${ }^{20}$.

In this way, from the premise that the muscles that make up the vocal apparatus are the same of the stomatognathic system, it is possible to assume that hoarseness and nasality symptoms may be included in the so-called Oral Breathing Syndrome (OBS) cases, 
since tone and /or postural changes in these muscles interfere with the performance of the speech and phonation functions ${ }^{21}$.

Analyzing the association between the presence of voice disorder and the breathing mode can contribute to speech-language therapy to achieve a better understand on the mechanism that integrates both aspects, which may facilitate a better planning of actions healing nature or aimed at the promotion of health and prevention of disorders in children.

The aim of this study was to analyze the association between voice disorder and aspects related to breathing mode (lip posture and nasal flow) in children, according to sex.

\section{METHODS}

This observational and cross-sectional study was approved by the Research Ethics Committee of the Pontifical Catholic University of São Paulo under the protocol number 216/2009 and the data collection was held, for convenience, in a primary school in the Northern area of São Paulo (attended by children from 06 to 14 years, a total of 1,456 students).

\section{Subject selection}

All children from six to nine years old who attended the school were invited to participate in this research: 44 with six years old; 129 with seven years old; 116 with eight years old, and 102 with nine years old, totaling 391 children. In order to check the correct age range, the school record book was used as provided by the school management.

The sample was constituted, as for sex, with a balanced amount of subjects (50.4\% - 126 female and $49.6 \%-124$ male), divided into the age groups that corresponded to $10 \%(25)$ at the age of six, $35.6 \%$ (89) at the age of seven, $30.8 \%(77)$ at the age of eight, and $23.6 \%$ (59) at the age of nine. The study selected only children in the appropriate health conditions to perform the assessment (no record of flu or allergic symptoms).

Before the data collection, a letter explaining the study was sent (via agenda) to the guardian of each child. A written informed consent form (WICF) was included to the letter in order to authorize the voice recording and the observation of the child's breathing mode.

Finally, after removing children who were not duly authorized by their guardians, the sample was composed of 250 .

\section{Procedures for data collection and analysis}

The procedures were initiated after selecting the quietest room in the school to collect the data relating to voice and breath aspects.

\section{Voice}

Due to the population composed of children, this study decided to collect only spontaneous speech samples in a playful activity. In order to find the best way to collect such a sample, we conducted a pilot study, with 24 children and six different stories (books). Finally, the story called "A Bruxinha Atrapalhada"22 was regarded as the easiest to the understanding of children and also the one that provided more spontaneous speech samples among the children. There are six figures in the story (illustrations without text) with beginning, middle and end.

The book was provided to each participant to be read, and then, the researcher, who should collect the data, and the children talked about the characters and the events in each figure.

In order to record the speech sample, there was a HD-75 headset microphone model of the Le Son brand, cardioid unidirectional, at a distance of about $5 \mathrm{~cm}$ from their mouth.

The Audacity (1.2.6 version) software was used to record data in a Compaq computer.

The record initiated with children sitting and telling their name, age and grade. Then, the child was asked to tell the plot of the book out loud, while holding the booking in their hands.

The material collected was not edited and it was composed of the whole narration of the story, as presented by the child, averaging 90 seconds and with an average interval of 2 seconds between each record.

\section{Analysis of speech samples}

The material was presented to three speechlanguage therapists as judges, who were specialized in voice and had at least five years of professional experience with children care. After signing the written informed consent form (WICF), the judges were instructed to rank the speech sample as to vocal quality.

The voice assessment was conducted through the perceptual-auditory analysis, according to the GIRBAS scale, which was created in 1969, and adapted in 1996. This scale assesses the general degree of dysphonia $(G)$ considering the level of instability $(I)$, roughness $(R)$, breathlessness $(B)$, asthenia $(A)$ and tension $(S)$, which are rated from 0 to 3 : 0 no changes; 1 slight changes; 2 moderate changes; e 3 intense changes ${ }^{23}$. 
In order to avoid overloading and consequently compromising listening, the 250 children / voices were divided into six groups, which corresponded to six meetings by the judges (average of 40 voices per meeting). Before every meeting, we conducted a previous training by listening eight voices (belonging to the sample that would not be assessed on the same day) to calibrate the parameters evaluated.

After the training, each judge should listen to a voice and record it, individually, in a specific protocol. In the end, the answers were discussed and, in case of no agreement, the voice was presented again. If a consensus was not reached, the assessment recorded by the majority was maintained.

\section{Breathing mode}

The observation and classification of the breathing of each child were performed on the same day, following the recording of the speech sample. Lip posture, in a drawing activity, and nasal flow, using the Glatzel mirror, were analyzed in this assessment.

\section{Lip Posture}

After recording the speech sample, the child received a blank sheet, a black pencil and an eraser and was asked to draw the story that was told earlier. Since the activity demanded silence, the child was instructed to not talk during the drawing and to not support their head. Then, during the activity, the researcher should be positioned in front of the child to assess the lip posture as: closed, opened: and sometimes opened, sometimes closed. The assessment was adapted from a model used in the orofacialmyofunctional assessment. The classification of the lip posture is recorded in the child's identification form.

\section{Nasal Flow}

The nasal flow was considered as reduced with the presence of nasal plaque condensation until the fourth line of the mirror (right/left or both sides), while an obstructed flow was regarded as the absence of plaque condensation (right/left or both sides). This decision is based on the clinical experience with children with breathing changes concerning the breathing mode.

After the drawing activity and lip posture classification, the child remained sitting while the researcher who was collecting data was positioned beside them to check the nasal air flow using a metal plate, which is the Glatzel mirror. This plate was placed horizontally under the nose of the child with the zero point of the mirror under the columella.

Then, the child was asked to perform a calm breathe, with no inspiratory or expiratory effort, keeping their eyes closed. The first condensation was discarded and the second one was marked with a pen in the mirror. This mark was used to observe nasal flow symmetry, reduction (right and left) and (right and left) obstruction.

This mark obtained through the mirror was transferred to a reference sheet through a manual copy with the transparency over the mirror.

\section{Data analysis}

The voice disorder in relation to the vocal quality was considered for statistical analysis as the presence of a deviation degree equal to or greater than "2", that is, a moderate and intense change as the result of ' $G$ ' from the GIRBAS assessment.

This decision is supported by studies that state that children up to 10 years old may present hyperfunctional voices due to physiological, social, environmental and emotional factors and, in isolation, it cannot be considered a dysphonic vocal behavior ${ }^{6,14}$.

The changed breathing was considered as the presence of lip posture, as sometimes opened and sometimes closed; and the presence of reduced (right / left) and obstructed (right / left) airflow.

A descriptive statistics was used through frequency distribution analysis of the variables, and the Chi-square test, $5 \%(p<0.05)$, statistical significance, to determine the association between the presence of voice disorder and gender (male and female) and the breathing mode with respect to the lip posture and nasal flow.

Data were introduced in Excel and analyzed in the SPSS software, version 22.0, for Windows.

\section{RESULTS}

With regard to the general degree of dysphonia $(G)$ with respect to the GIRBAS scale, slightly more than half of the children (131-52.4\%) presented some degree of change in vocal quality. When the parameters changed were detailed, it could be noted that most of the children showed no instability (I), 246 (98.4\%) and none of them presented asthenia $(A)$, or in intense degree in breathlessness and tension parameters (Table 1). 
Table 1. Distribution of subjects with respect to the general degree of dysphonia $(G)$, instability $(I)$, roughness $(R)$, breathlessness $(B)$, asthenia $(A)$ and tension $(S)$, in the respective levels of change

\begin{tabular}{ccccccccccccc}
\hline Level of & \multicolumn{2}{c}{$\mathbf{G}$} & \multicolumn{1}{c}{$\mathbf{I}$} & \multicolumn{3}{c}{$\mathbf{R}$} & \multicolumn{3}{c}{$\mathbf{3}$} & $\mathbf{A}$ & \multicolumn{3}{c}{$\mathbf{S}$} \\
\cline { 2 - 14 } Change & $\mathbf{n}$ & $\%$ & $\mathbf{n}$ & $\%$ & $\mathbf{n}$ & $\%$ & $\mathbf{n}$ & $\%$ & $\mathbf{n}$ & $\%$ & $\mathbf{n}$ & $\%$ \\
\hline 0 & 119 & 47.6 & 246 & 98.4 & 157 & 62.8 & 129 & 51.6 & 250 & 100 & 185 & 74.0 \\
1 & 99 & 39.6 & 2 & 0.8 & 74 & 29.6 & 99 & 39.6 & 0 & 0 & 58 & 23.2 \\
2 & 28 & 11.2 & 1 & 0.4 & 17 & 6.8 & 22 & 8.8 & 0 & 0 & 7 & 2.8 \\
3 & 4 & 1.6 & 1 & 0.4 & 2 & 0.8 & 0 & 0 & 0 & 0 & 0 & 0 \\
\hline
\end{tabular}

Legend: 0: no changes; 1 : slight changes; 2: moderate changes; and 3: intense changes

With regard to the general degree of dysphonia $(G)$, there was a slight occurrence in the absence of the alteration in females (63-25.2\%), while the same also occurred in the slight (51-20.4\%), and moderate (15-6.0\%) changes.
Of the 250 children, 32 (12.8\%) presented voice disorder (grades 2 and 3 on the scale) concerning vocal quality, in equal numbers for each gender (16-6.4\%). However, girls prevailed in intense degree (Table 2).

Table 2. Distribution of subjects with respect to the general degree of dysphonia $(G)$, in the respective levels of change, according to the gender

\begin{tabular}{|c|c|c|c|c|c|}
\hline \multirow{3}{*}{ Level of dysphonia } & \multicolumn{5}{|c|}{ Gender } \\
\hline & \multicolumn{2}{|c|}{ males } & \multicolumn{2}{|c|}{ females } & \multirow{2}{*}{ Total } \\
\hline & $n$ & $\%$ & $n$ & $\%$ & \\
\hline 0 & 57 & 46 & 62 & 49.2 & 119 \\
\hline 1 & 51 & 41.2 & 48 & 38 & 99 \\
\hline 2 & 15 & 12 & 13 & 10.4 & 28 \\
\hline 3 & 1 & 0.8 & 3 & 2.4 & 4 \\
\hline Total & 124 & 100 & 126 & 100 & 250 \\
\hline
\end{tabular}

Legend: 0: no changes; 1: slight changes; 2: moderate changes; and 3: intense changes

With respect to breathing mode variables, 158 (63.2\%) of the children present closed lip posture, with greater occurrence in females (91-36.4\%). Of 92 that presented some change in this aspect (lips sometimes opened/sometimes closed and opened/half opened), $57(22.8 \%)$ were male, with a statistically significant evidence to this association $(p=0.003)$.
With respect to nasal flow, there was higher occurrence of females concerning symmetric flow, 39 (15.6\%), and in the presence of such change (reduced and obstructed flow), for males, 91 (36,4\%), which, however, did not supported a statistically significant difference $(p=0.449)$ (Table 3$)$. 
Table 3. Distribution of subjects with respect to the association of breathing mode, in lip posture (closed, sometimes opened / sometimes closed, opened and half opened) and nasal flow (systemic, reduced to the right or to the left, obstructed to the right or to left), according to the gender

\begin{tabular}{ccccccc}
\hline \multirow{2}{*}{ Breathing mode } & \multicolumn{5}{c}{ Gender } \\
\cline { 2 - 5 } & \multicolumn{3}{c}{ males } & females & \multirow{2}{*}{ p-value } \\
\cline { 2 - 5 } & $\mathbf{n}$ & $\%$ & $\mathbf{n}$ & $\%$ & \\
Lip Posture & 67 & 26.8 & 91 & 36.4 & \\
Closed & 49 & 19.6 & 31 & 12.4 & \\
Sometimes opened / sometimes closed & 8 & 3.2 & 4 & 1.6 & 0.003 \\
Opened / half opened & 33 & 13.2 & 39 & 15.6 & \\
Nasal flow & 78 & 31.2 & 84 & 33.6 & \\
Symmetric & 13 & 5.2 & 3 & 1.2 & 0.449 \\
Reduced & & & & & \\
Obstructed & & & & & & \\
\hline
\end{tabular}

Chi-square test $(p=0.05)$

Of the 32 children that presented voice disorder related to vocal quality, there was a slightly higher occurrence in males, 16 (12.9\%), which, however, did not provided a statistically significant evidence $(p=0.96)$.
The association of voice disorder and breathing mode, in lip posture $(p=0.38)$ and nasal flow $(p=0.18)$, did not supported a statistically significant difference; although there was a higher occurrence in lip posture change and nasal flow change in children with voice disorders (Table 4).

Table 4. Distribution of subjects concerning the association of voice disorder (presence and absence), with respect to vocal quality, in gender and breathing mode, in lip posture and nasal flow

\begin{tabular}{|c|c|c|c|c|c|c|}
\hline \multirow{3}{*}{ Aspect } & \multicolumn{4}{|c|}{ Voice Disorder } & \multirow{3}{*}{ Total } & \multirow{3}{*}{$P$ value } \\
\hline & \multicolumn{2}{|c|}{ Presence } & \multicolumn{2}{|c|}{ Absence } & & \\
\hline & $\mathrm{n}$ & $\%$ & $\mathbf{n}$ & $\%$ & & \\
\hline \multicolumn{7}{|l|}{ Gender } \\
\hline Males & 16 & 12.9 & 108 & 87.1 & 124 & \\
\hline Females & 16 & 12.7 & 110 & 87.3 & 126 & 0.96 \\
\hline \multicolumn{7}{|l|}{ Breathing mode } \\
\hline \multicolumn{7}{|l|}{ Lip Posture } \\
\hline No Changes & 18 & 11.4 & 140 & 88.6 & 158 & \\
\hline $\begin{array}{c}\text { Presence of change } \\
\text { Nasal flow }\end{array}$ & 14 & 15.2 & 78 & 84.8 & 92 & 0.38 \\
\hline No Changes & 6 & 8.3 & 66 & 91.7 & 72 & \\
\hline Presence of change & 26 & 14.6 & 152 & 85.4 & 178 & 0.18 \\
\hline
\end{tabular}

Chi-square test $(p=0.05)$

\section{DISCUSSION}

There are many signals that indicate the presence of a vocal change, which can be represented from the hoarseness and breathlessness to the compromised vocal efficacy, such as fatigue and tiredness during phonation ${ }^{24}$.
However, there are many disagreements and discussions about what should be regarded as a normal voice for children. It is known that there are anatomical and physiological characteristics that distinguish the larynx in adults and children. There are several aspects, such as the position of the neck, the size of vocal cords, the differentiation of the layers of the plate and vocal 
ligament (until 13 years old to females and 15 years old to males), as well as social, environmental and emotional factors, that make children population more likely to the presence of vocal disorders ${ }^{4}$.

In this study, it was observed the presence of vocal disorder in a percentage that is compatible with the one reported in the literature that describes it as ranging from 6 to $9 \%$, which may reach 17\%, when analyzed in an expanded age range between two to 16 years old $^{24,25}$.

It is important to notice that even showing aspects that provide the high incidence of vocal change in this population, by factors previously described, the social acceptance on a voice disorder case is high, and often a symptom of hoarseness is not regarded as a health problem. The work focused on issues related to vocal well-being awareness and promotion continues to be the main way of preventing vocal changes in children, which favors their insertion in school, family, and social environments, and even in the choice of a future profession.

Some authors ${ }^{24,26}$ point out the predominance of vocal changes in males, in the age range from seven to nine years. Such relationship would be explained by behavioral factors, since even the vocal change there are no anatomical or physiological differences that justify the greater occurrence. According to these authors, the behavioral factors would be related to situations of competition, leadership, aggressiveness, which are more common among boys, engaged in school and sports situations that require excessive use of voice.

However, it can be observed in this study that there was no statistical difference, regarding the gender in the association with the voice disorder. This probably is related to the changes in the family context which includes a growing insertion of women in professional and social situations that require a more active communicative role and it may be contributing to more abusive vocal models among girls and, consequently, lesions of vocal folds more frequent in this gender ${ }^{27}$.

With respect to the subjective analysis of the voice, the perceptual-auditory analysis is pointed as a routine procedure in global clinical practice, and it has been considered an effective tool in detecting vocal changes $^{28,29}$. For this analysis, the GIRBAS scale is referred in studies as the more fast and reliable method in the perceptual-auditory analysis ${ }^{28,30-32}$.

Even though the literature researched indicates a preference in the use of this scale, there are differences as to what to recommend in this type of evaluation, as well as to the definition of a nomenclature that clarifies the mentioned requests for directed questions, counting of numbers and narration of texts.

Several collecting methods are mentioned in the literature. Some authors mention the emission of sustained vowels, connected/automatic/spontaneous/ directed speech, emission of automatisms, or reading of texts ${ }^{4,32,33}$.

Due to the population composed of children, this study decided to collect only spontaneous speech in a playful activity. Thus, the samples were characterized as from the same narrative context, but with significant diversity of the participants, which favored the assessment recommended.

For the speech-language pathology practice with regard to breath, the use of the Glatzel mirror is recommended in the nasal function in order to observe the symmetry of the air flow between the nostrils. Some authors have used the same instrument to evaluate changes in nasal flow during breathing after a therapeutic intervention in children ${ }^{34}$, and others used it to analyze the nutritional effects of oral breathing in children ${ }^{15}$. Therefore, the use of this instrument to capture the nasal airflow in this research, is consistent with the literature.

This study showed a high incidence of changes in this aspect (in the presence of reduced or obstructed flow to the right or to the left, with absence of total obstruction) and a slight predominance in boys. There is a record of high incidence of breathing disorders in children in the literature, which may be associated from small allergic processes to sleep apnea ${ }^{21}$.

In addition, the occurrence of breath change in this study can be explained by the fact that the nasal flow was collected without cleaning the upper airways. This cleaning is suggested by authors ${ }^{23}$ and such a procedure, which was not performed in this study, is justified by the hypothesis that the cause of the nasal obstruction was not sought, but rather the presence of a frequent obstruction (either organic by and/or functional cause, including poor hygiene) that may contribute to the onset of a vocal disorder. In addition, the way that the upper airway is cleaned could be susceptible to innumerable variations, due to the different ways each child would understand and perform the procedure.

The lip posture, which is another aspect mentioned in this study, is a myofunctional characteristic that is highlighted in studies aimed at oral breathing ${ }^{11,13}$. The authors highlighted that the presence of opened lips 
in usual rest situation is one of the aspects indicative of oral breathing ${ }^{35}$, although in some cases the subject may keep the lips half opened and also nasal breathing.

The oral breather usually has opened lips with tone change, when the upper lip can be retracted or shortened, while the lower one may present a dry and cracked appearance ${ }^{36}$.

The change in lip posture has occurred in greater numbers among males, which can be explained by the factors described previously. Males tend to present a higher incidence of breathing changes with respect to breathing mode. Inadequate lip posture is one of the aspects that the oral breather usually presents in order to facilitate the entry of air through the mouth, thus making the male population more likely to present the change.

No study analyzing the association of voice disorder and lip posture was found. In addition, the results of this study did not support a statistically significant relevance. However, it is important to note that, with the lowering of the jaw and consequent loss of lip contact, the positioning of the hyoid bone would be changed, whose muscles (supra and infra-hyoid) would change the movement of the laryn $x^{21}$. Consequently, the dryness of the laryngeal tissues, through an opened lip posture, would hinder the vocal fold vibration.

With regard to the association of voice disorder with nasal flow, the literature indicated the presence of a relationship between oral breathing and dysphonia, with concluded that there is still a shortage of studies associating these two aspects ${ }^{21}$. Thus, since this research address a subject that lacks discussion, it contributes to a wider scientific knowledge, facing a frequent clinical reality, with patients often presenting both changes.

However, we observed some studies in the literature highlighting the relationship of voice disorder, in the presence of the nasal flow change due to different causes especially in allergic, tumors and nasal polyps cases and/or hypertrophy of pharyngeal tonsil (adenoid), when the obstructive processes of upper airways occur with the reduction of the nasal component ${ }^{10}$.

The resulting voice is called hyponasal, whose characteristics are muffled vocal quality and lack of quality in harmonics. The effects of allergic processes on voice are reported in different studies ${ }^{14,26}$.

The palatine tonsils (tonsils) are lymphatic organs that are developed between the anterior and posterior pillars of the soft palate. With respect to the hypertrophy of the palatine tonsils (tonsils), there may be a change in the intraoral cavity by a change in the position of the tongue (anterior inferior), which may hinder the vocal resonance and emission ${ }^{10}$.

It could be observed in the literature that there is a greater focus on the association of nasal airflow change with voice disorder in the ressonantal aspect. Therefore, breathing changes of upper airways would be linked to changes in the definitions of the vocal tract (filter), which was not the subject of this research, since it proposed a perceptual-auditory analysis of the characteristics of glottal source in a group of children, associated with the breathing changes.

In this way, what often determines a vocal disorder in children may be related to the vocal tract and not to the larynx, that is, the issues are linked to the source, not to the filter. The acoustic result generated by the vibration of the vocal folds and the filter function is called source, which results in an acoustic result depending on the specific form and length of the tract ${ }^{13}$.

The vibrations generated by the vocal folds (frequency, intensity and duration) are modified by the structures between them and the opening of the mouth. The tongue, lips, pharynx, palate and nasal cavity modify the quality of the sound produced by the larynx, which provides substantial changes in the voice, related to the resonance ${ }^{10}$.

Finally, this research highlights the importance of the continuity of other studies that address voice and breathing, and are directed to analyze related to the vocal result of the combination between source and filter, due to the scarcity of literature that addresses the subject and to provide more opportunities of care for children who present changes in both aspects.

\section{CONCLUSION}

There was no statistically significant difference associating voice disorders with breathing mode (lip posture and nasal flow) and gender. Based on the group analyzed and with respect to vocal quality, the voice disorder occurrence in children is consistent with the literature.

\section{REFERENCES}

1. Ferreira LP. Assessoria fonoaudiológica aos profissionais da voz. In: Fernandes F, Mendes BCA, Navas ALPGP (ed). Tratado de Fonoaudiologia. 2. São Paulo: Rocca; 2009. p. 746. 
2. Erdur O, Herguner A, Ozturk K, Kibar E, Elsurer C, Bozkurt MK et al. Attention deficit hyperactivity disorder symptoms in children with vocal fold nodules. Int. J. Pediatr. Otorhinolaryngol. 2016;85:5-7.

3. Dornelles CEAPA. Correlação entre avaliação perceptiva auditiva e nasofibroscopia em crianças sem queixa vocal. Revista da AMRIGS. 2007;51(2):121-7.

4. Oliveira RC, Teixeira LC, Gama ACC, Medeiros AM. Auditory-perceptive, acoustic and vocal self-perception analyses in children. J Soc Bras Fonoaudiol. 2011;23(2):158-63.

5. Negrão MC. Levantamento de hábitos vocais em alunos de pré a 4 a série de uma escola pública municipal de Curitiba [Dissertação]. Curitiba (PR): Universidade Tuiuti do Paraná; 2008.

6. Behlau M. O livro do especialista. v. I. Rio de Janeiro: Revinter. 2008.

7. Silva EF. A voz dentro da relação psíquicoorgânica: estudo sobre a influência das emoções na voz do ator. R. Cient. FAP. 2009;4(1):1-19.

8. Roy N, Barkmeier-Kraemer J, Eadie T, Sivasankar MP, Mehta D, Paul D et al. Evidence-based clinical voice assessment: a systematic review. Am J Speech Lang Pathol. 2013;22(2):212-26.

9. Ockel E. Contributions to Speech Science I: Selected Writings in The Therapy of Voice, Speech-, Voice- and Breathing Disorders, with an Audio-CD. Muttersprache. 2014;124(1):97-100.

10. Marchesan IQ, Krakauer L. A importância do trabalho respiratório na terapia miofuncional. In: Marchesan IQ, Bolaffi C, Gomes ICD, Zorzi JL (ed). Tópicos em Fonoaudiologia. 2. São Paulo: Lovise; 1995. p. 155-60.

11. Rodrigues H, Faria SR, Paula F, Motta AR. Ocorrência de respiração oral e alterações miofuncionais orofaciais em sujeitos em tratamento ortodôntico. Rev Cefac. 2005;7(3):356-62.

12. Gallo J, Campiotto AR. Terapia Miofuncional Orofacial em crianças respiradoras orais. Rev. CEFAC. 2009;11(3):305-10.

13. Andrada e Silva MA, Marchesan IQ, Ferreira LP, Schmidt R, Ramires RR. Postura, tônus e mobilidade de lábios e língua de crianças respiradoras orais. Rev. CEFAC 2012;14(5):853-60.

14. Takeshita TK, Aguiar-Ricz L, de Lima Isaac M, Ricz $H$, Anselmo-Lima W. Vocal Behavior in Preschool Children. Intl Arch Otorhinolaryngol. 2009;13(3):252-8.
15. Castro Martinelli RLd, Fornaro EF, Oliveira CJMd, Ferreira LMDB, Rehder MIBC. Correlations between speech disorders, mouth breathing, dentition and occlusion. Rev. CEFAC. 2011;13(1):17-26.

16. Marchesan IQ. O trabalho fonoaudiológico nas alterações do sistema estomatognático. In: Marchesan IQ, Bolaffi C, Gomes ICD, Zorzi JL (eds). Tópicos em fonoaudiologia. 1. São Paulo: Lovise; 1994. p. 83-96.

17. Freitas MR, Pela S, Gonçalves ML, Fujita RR, Pontes PA, Weckx LL. Disfonia crônica na infância e adolescência: estudo retrospectivo. Rev Bras Otorrinolaringol. 2000;66(5):480-4.

18. Tavares ELM, Martins RHG, Santana MF, Carvalho RL, Labi ORB, Gonçalves T. Prevalência de distúrbios vocais em escolares de 4 a 12 anos baseada na análise da impressão subjetiva dos pais com relação à voz do seu filho. In: Anais do 18ㅇ Congresso Brasileiro de Fonoaudiologia, 2010, Curitiba. XVIII Congresso Brasileiro de Fonoaudiologia: Exercício Profissional: Bases Teóricas, Avanço e Realidade Nacional. São Paulo: SBFa, 2010. v. 18. p. 3921-3921.

19. Berwig LC, Silva AMT, Busanello AR, Almeida FL, Bolzan GP, Hennig TR et al. Alterações no modo respiratório, na oclusão e na fala em escolares: ocorrências e relações. Rev. CEFAC. 2010;12(5):795-802.

20. Nishimura CM, Gimenez S. Perfil da fala do respirador oral. Rev. CEFAC. 2010;12(3):505-8.

21. Tavares JG, Silva EHAA. Considerações teóricas sobre a relação entre respirador oral e disfonia. Rev Soc Bras Fonoaudiol. 2008;13(4):405-10.

22. Furnari E. A bruxinha atrapalhada. 24 ed. São Paulo: Global; 2003.

23. Marchesan IQ, Berretin-Félix G, Flores Genaro K. MBGR protocol of orofacial myofunctional evaluation with scores. Int $\mathrm{J}$ Orofacial Myology. 2012;38(1):38-77.

24. Azevedo R. Disfonia na infância. In: Fernandes FDM, Mendes BCA, ALPGP N (eds). Tratado de Fonoaudiologia. 2 ed. Säo Paulo: Ed. Roca. 2010. p.700-08.

25. Martins RHG, Tavares ELM, Ranalli PF, Branco A, Pessin ABB. Psychogenic dysphonia: diversity of clinical and vocal manifestations in a case series. Braz J Otorhinolaryngol. 2014;80(6):497-502. 
26. Ribeiro VV, Leite APD, Alencar BLF, Bail DI, Bagarollo MF. Evaluating the dynamic vocal dysphonic children in a pre and post intervention speech therapy group: a case stud. Rev. CEFAC. 2013;15(2):485-94.

27. Tavares ELM, Brasolotto A, Santana MF, Padovan CA, Martins RHG. Estudo epidemiológico de disfonias em crianças de 4 a 12 anos. Braz J Otorhinolaryngol. 2011;77(6):736-46.

28. Corazza VR, Silva VFCd, Queija DS, Dedivitis RA, Barros APB. Correlação entre os achados estroboscópicos, perceptivo-auditivos e acústicos em adultos sem queixa vocal. Rev Bras Otorrinolaringol. 2004;70(1):30-4.

29. Nemr K, Amar A, Abrahão M, Leite GCA, Köhle $\mathrm{J}$, Santos $A O$ et al. Análise comparativa entre avaliação fonoaudiológica perceptivo-auditiva, análise acústica e laringoscopias indiretas para avaliação vocal em população com queixa vocal. Rev Bras Otorrinolaringol 2005;71(1):13-7.

30. Dejonckere P. Voice problems in children: pathogenesis and diagnosis. International Journal of Pediatric Otorhinolaryngology. 1999;49:S311-S4.

31. Teles VC, Rosinha ACU. Análise acústica dos formantes e das medidas de perturbação do sinal sonoro em mulheres sem queixas vocais, não fumantes e não etilista. Arq int otorrinolaringol. 2008;12(4):523-30.

32. Carrasco ER, Oliveira G, Behlau M. Análise perceptivo-auditiva e acústica da voz de indivíduos gagos. Rev. CEFAC. 2010;12(6):925-35.

33. Silva CLM. Fala espontânea e leitura oral no português do Brasil: comparação por meio de análise acústica [Dissertação]. São Paulo 5SP): Universidade de São Paulo; 2008.

34. Melo FMG, Cunha DA, Silva HJ. Avaliação da aeração nasal pré e pós a realização de manobras de massagem e limpeza nasal. Rev. CEFAC. 2007;9(3):375-82.

35. Junqueira P, Parro FM, Toledo MR, Araújo R, Di Francesco R, Rizzo MC. Conduta fonoaudiológica para pacientes com diagnóstico de rinite alérgica: relato de caso. Rev. CEFAC. 2005;7(3):336-9.

36. Andrada e Silva MA, Natalini V, Ramires RR, Ferreira LP. Análise comparativa da mastigação de crianças respiradoras nasais e orais com dentição decídua.

Rev. CEFAC. 2007;9(2):190-8. 